03. 1;10

\title{
Снижение уровня звукового удара с помощью разогрева набегающего потока
}

\author{
() А.В. Потапкин, Д.Ю. Москвичев \\ Институт теоретической и прикладной механики им. С.А. Христиановича СО РАН, Новосибирск, Россия \\ E-mail: potapkin@itam.nsc.ru
}

Поступило в Редакцию 25 февраля 2019г.

В окончательной редакции 25 февраля 2019г.

Принято к публикации 4 марта 2019г.

\begin{abstract}
Представлены результаты расчетов уровня звукового удара, возникающего при локальном разогреве потока воздуха перед тонким телом, совершающим сверхзвуковой полет в тепловом следе за областями нагрева. Число Маха холодного потока воздуха равно 2. Расчеты выполнены с помощью комбинированного метода „тел-фантомов“. Показано, что локальный последовательный разогрев набегающего потока в двух областях перед телом обеспечивает снижение уровня звукового удара более чем на $30 \%$ по сравнению с уровнем звукового удара от тела в холодном потоке.
\end{abstract}

DOI: 10.21883/PJTF.2019.10.47756.17751

В настоящее время звуковой удар является основной проблемой, препятствующей развитию и эксплуатации сверхзвуковой гражданской авиации. Разрабатываются различные способы снижения уровня звукового удара от сверхзвукового самолета. Например, в работе [1] предлагалось разогревать атмосферу вокруг самолета в локальной области определенной формы с контролируемым распределением температуры в области. Расчеты показали, что разогрев атмосферы вокруг самолета может обеспечить эффект снижения звукового удара. Известно и техническое решение проблемы звукового удара [2]. Предлагалось подводить лучистую энергию к набегающему потоку воздуха вдоль передней кромки крыла самолета, что может обеспечить дозвуковое обтекание крыла и ослабление звукового удара. В патенте не принимались во внимание ударные волны от области нагрева потока и их роль в формировании звукового удара в дальнем поле.

Экспериментальные и теоретические исследования уменьшения интенсивности ударной волны от тела при разогреве воздуха с помощью лазерного излучения представлены в работе [3]. Исследования показали, что подвод энергии и разогрев набегающего потока около тела могут быть использованы для снижения интенсивности ударных волн в ближнем поле.

Расширенный обзор работ по проблеме звукового удара можно найти в [4].

Большое количество факторов определяет динамику ударных волн. Измерения параметров ударных волн можно выполнить в аэродинамических трубах с локальным нагревом сверхзвукового потока, но из-за малых размеров рабочей части аэродинамических труб невозможно проводить измерения параметров ударных волн на больших расстояниях от тела. В настоящее время отсутствуют натурные эксперименты и эксперименты в баллистических трассах с нагревом сверхзвукового потока возле самолета. Поэтому основным инструмен- том для решения этих задач являются аналитические и численные методы.

Для расчета параметров слабых ударных волн на больших расстояниях от места их возникновения был разработан комбинированный численно-аналитический метод, в котором использовались аналитические решения Ландау [5], Уизема [6] и Рао [7]. Метод построен на последовательном выполнении расчетов ближнего и дальнего поля течения. Он получил название метода ,тел-фантомов“ [8].

Тестирование метода „тел-фантомов“ выполнено в работах [8-10]. С помощью этого метода проведены расчеты интенсивности головной ударной волны от тонкого тела вращения (число Маха набегающего потока $\left.\mathrm{M}_{0}=2.4\right)$ и затупленных тел $\left(\mathrm{M}_{0}=2.0\right)$. Поверхность тонкого тела задавалась формулой

$$
\tilde{r}=0.2\left(x-x^{2}\right),
$$

где $\tilde{r}$ - радиальная координата образующей поверхности тела, $x$ - продольная координата, отсчитываемая от носика тела вниз по потоку $(0 \leqslant x \leqslant L)$. На рис. 1 показано сравнение результатов расчетов с аналитическими и численными решениями, а также с результатами экспериментов в баллистической трассе. Здесь введены следующие обозначения: $\Delta p-$ интенсивность головной ударной волны, $p_{0}-$ статическое давление в набегающем потоке, $r$ - расстояние от траектории полета, $L$ - длина тела, $d$ - диаметр тела, $h$ - расстояние от траектории полета до мерной пластины. Сравнение результатов на рис. 1, $a$ показало, что решения в дальнем поле, полученные с помощью различных методов, отличаются друг от друга не более чем на $2 \%$. Это гарантирует правильность расчетов дальнего поля по методу „тел-фантомов“ для тонких тел с присоединенными ударными волнами и отсутствием областей с дозвуковым течением. В то же время в методе „тел-фантомов“ начальные данные для нахождения 

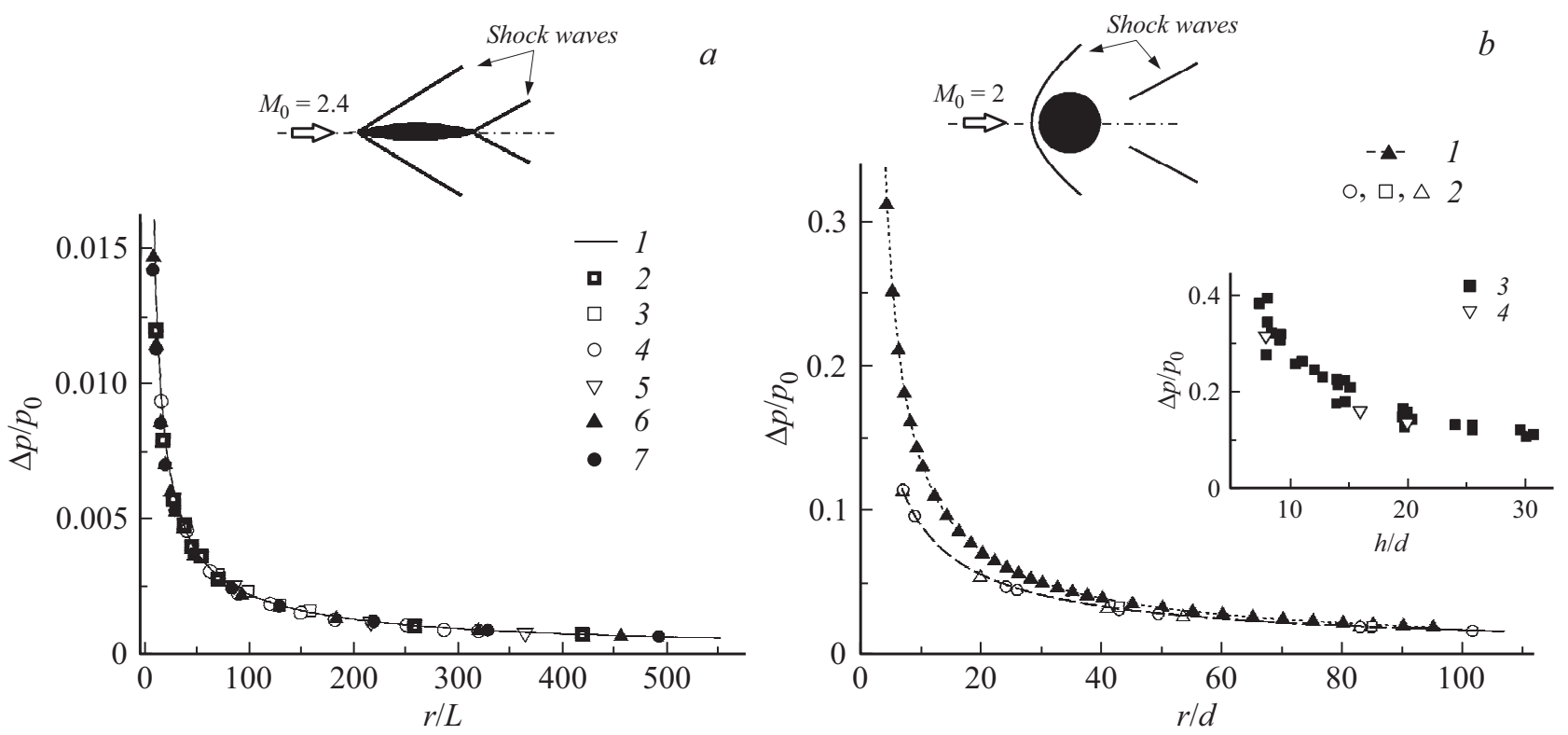

Рис. 1. Тестирование метода „тел-фантомов“. $a$ - заостренное тело вращения: 1 - зависимость $\Delta p / p_{0} \sim(r / L)^{-3 / 4}[5]$, 2 - расчеты по теории Уизема [6], 3-5 - расчеты динамики ударных волн в подвижных разностных сетках с использованием уравнений Эйлера [9], 6, 7 - расчеты по методу „тел-фантомов“ $[8] ; b-$ затупленное тело вращения: $1,4-2 \mathrm{D}-$ и 3D-расчеты с использованием уравнений Навье-Стокса, 2 - расчеты по методу „тел-фантомов“ [10], 3 - эксперименты в баллистической трассе [11].
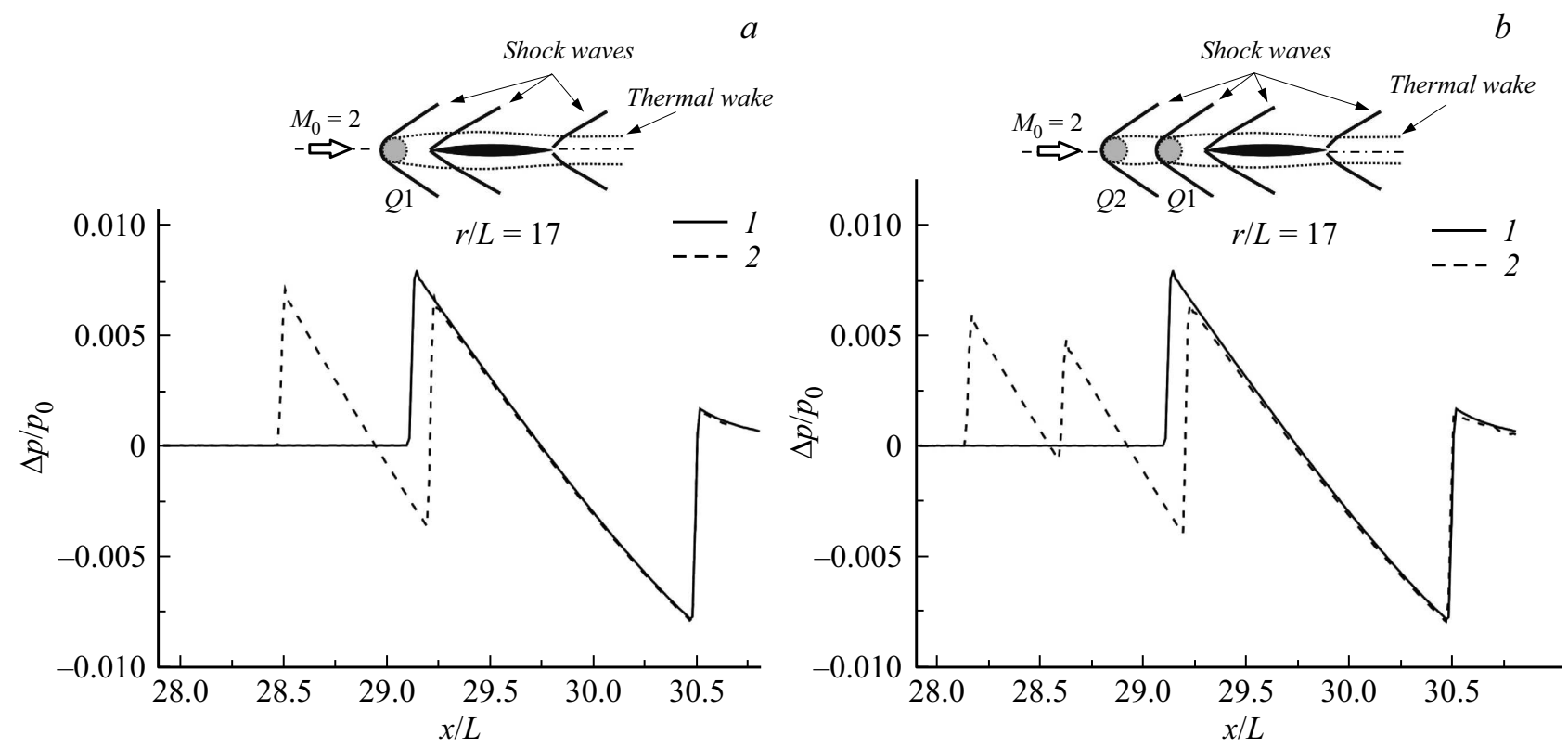

Рис. 2. Схема течения и распределение избыточного давления под телом в ближнем поле. $a$ - одна область нагрева потока $Q 1$ перед телом, $b$ - две области нагрева $Q 1$ и $Q 2$ перед телом. 1 - профиль давления для тела в потоке без теплоподвода, 2 - профили давления для тела в потоке с подводом тепла.

решения в дальнем поле берутся на таких расстояниях от траектории полета, на которых течение является сверхзвуковым. Возможность расчета звукового удара от затупленных тел с отошедшей ударной волной изучалась на примере задачи об обтекании шара сверхзвуковым потоком газа в работе [10]. Результаты тестирования показаны на рис. $1, b$. В качестве тестового материала использовались результаты экспериментальных исследований звукового удара с шарами разного диаметра в баллистических трассах и аэродинамических трубах [11]. Тестовые расчеты показали, что метод „тел-фантомов“ применим для вычисления параметров ударных волн в дальнем поле как от заостренных, так и от затупленных тел. 
$a$

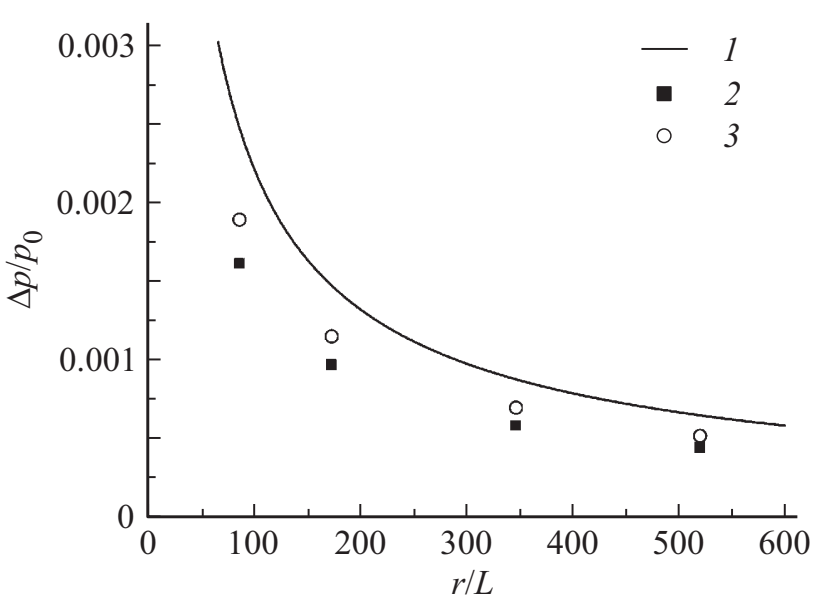

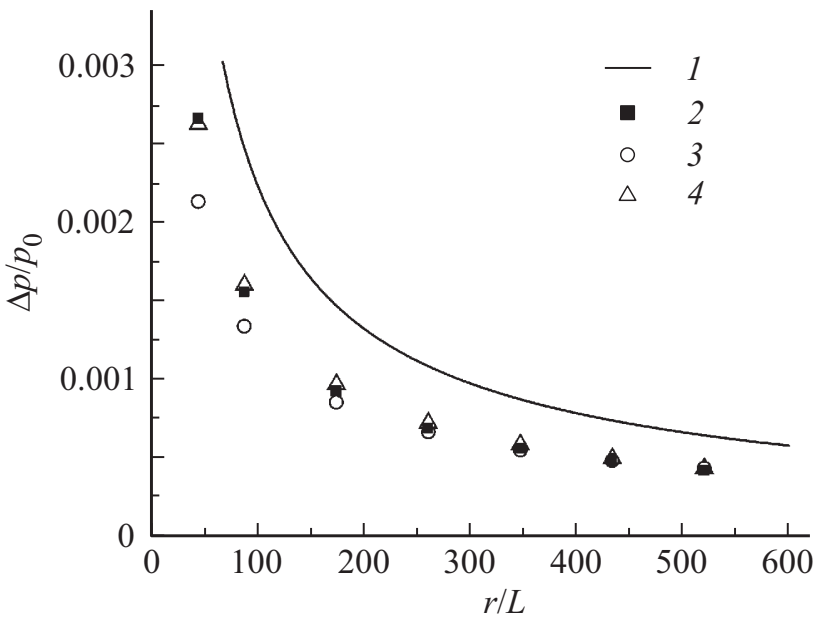

Рис. 3. Интенсивность ударных волн в дальнем поле. $a$ - одна область нагрева потока $Q 1, b-$ две области нагрева $Q 1$ и $Q 2$. 1 - зависимость $\Delta p / p_{0} \sim(r / L)^{-3 / 4}$ [5] для интенсивности ударной волны от тела в холодном потоке, $2-$ интенсивность ударной волны от тела, находящегося в тепловом следе, 3 - интенсивность ударной волны от области нагрева $Q 1,4-$ интенсивность ударной волны от области нагрева $Q 2$.

Когда в набегающий поток перед телом подводится тепло, картина течения становится похожей на картину течения около затупленного тела. В окрестности области теплоподвода формируется ударная волна, а за областью теплоподвода формируется тепловой след с повышенной температурой потока, пониженной плотностью и пониженными значениями чисел Маха.

Форма, размер области теплоподвода и ее положение относительно тела влияют на условия обтекания тела, находящегося в тепловом следе, и на интенсивность ударных волн от тела [9]. На рис. 2 показаны схемы течения вблизи локальных областей нагрева $Q 1, Q 2$ и тонкого тела. Для этих схем течения выполнены расчеты ближнего и дальнего поля течения. Расчеты ближнего и среднего полей течения проводились с помощью пакета программ ANSYS Fluent с использованием модели вязкого теплопроводного газа. Использовалась система двумерных уравнений Навье-Стокса, дополненных моделью турбулентности Спаларта-Аллмараса. Параметры расчета были следующими: $\mathrm{M}_{0}=2, L=1 \mathrm{~m}$, $p_{0}=101325 \mathrm{~Pa}, T_{0}=300 \mathrm{~K}\left(T_{0}\right.$ - статическая температура в набегающем потоке воздуха). Области нагрева $Q 1$ и $Q 2$ имели форму шара с радиусом $0.05 L$ при постоянной удельной мощности энергоподвода $1.75 \cdot 10^{9}$ и $1.2 \cdot 10^{9} \mathrm{~W} / \mathrm{m}^{3}$ соответственно. Область $Q 1$ была расположена на расстоянии $0.5 L$ перед носиком тонкого тела, область $Q 2$ - на расстоянии $0.9 L$ перед носиком тела. Результаты расчетов ближнего поля использовались в качестве начальных данных для расчетов дальнего поля по методу „тел-фантомов“.

На рис. 2, $а$ показаны результаты расчетов для одной области нагрева потока $Q 1$. Наибольшая температура воздуха в области нагрева была равна $1.93 T_{0}$. Поле давления под телом на расстоянии $r / L=17$ от траектории полета показано с помощью профилей относительного избыточного давления $\Delta p / p_{0}$ вдоль продольной координаты $x$. Размер области нагрева потока $Q 1$, температура воздуха в области $Q 1$ и положение области $Q 1$ относительно тела влияют на интенсивность ударных волн и их динамику. При разогреве потока воздуха перед телом происходит увеличение скорости звука и уменьшение числа Маха потока в тепловом следе. В потоке формируется ударная волна от области $Q 1$. Интенсивность этой волны растет с ростом температуры в области нагрева. Существуют пороговые значения размера области нагрева и температуры нагрева потока, выше которых интенсивность ударной волны от области нагрева $Q 1$ становится больше интенсивности ударной волны от тела в холодном потоке. В этом случае звуковой удар будет определяться ударной волной от области нагрева потока. Поэтому первым условием снижения уровня звукового удара будет выбор размера области $Q 1$ и выбор температуры нагрева потока, обеспечивающих приемлемые значения интенсивности ударных волн в ближнем поле. Вторым условием снижения уровня звукового удара будет выбор расстояния между областью нагрева $Q 1$ и телом. Для снижения звукового удара область нагрева потока должна располагаться на таких расстояниях от тела, при которых исключается слияние ударных волн от области нагрева и от тела в дальнем поле. В противном случае слияние ударных волн в дальнем поле приведет к увеличению уровня звукового удара [9]. Жесткое ограничение по температуре потока в тепловом следе при решении задачи уменьшения уровня удара можно снять с помощью последовательного разогрева потока. На рис. 2, $b$ представлены результаты расчетов для двух областей нагрева $Q 1$ и $Q 2$. Поток нагревался в области $Q 2$ до наибольшей температуры $1.63 T_{0}$, в 
области $Q 1$ поток нагревался до температуры $2.8 T_{0}$. При последовательном разогреве набегающего потока удается уменьшить интенсивность ударных волн по сравнению с интенсивностью ударных волн от тела в холодном потоке.

Расчеты интенсивности ударных волн в дальнем поле показаны на рис. 3.

Разогрев набегающего сверхзвукового потока в одной области, расположенной перед телом, уменьшает уровень удара примерно на 20\%. Последовательный разогрев потока в двух областях позволяет снизить уровень звукового удара более чем на $30 \%$ по сравнению с уровнем удара от тела в холодном потоке.

Таким образом, можно сделать вывод, что пошаговый разогрев набегающего потока в нескольких последовательно расположенных областях теплоподвода обеспечивает существенное снижение уровня звукового удара по сравнению с уровнем удара от тела в холодном потоке.

\section{Финансирование работы}

Работа выполнена в рамках Программы фундаментальных научных исследований государственных академий наук на 2017-2020 гг. (проект AАAА-A17117030610126-4).

\section{Конфликт интересов}

Авторы заявляют, что у них нет конфликта интересов.

\section{Список литературы}

[1] Miller D.S., Carlson H.W. A study of the application of heat or force fields to the sonic-boom-minimization problem. NASA TN D-5582. Washington, 1969. $17 \mathrm{p}$.

[2] Riley J.K. Sonic boom attenuator. US Patent 5,263,661. 1993.

[3] Zaidi S.H., Shneider M.N., Miles R.B. // AIAA J. 2004. V. 42. N 2. P. 326-331.

[4] Sun Y., Smith H. // Prog. Aerospace Sci. 2017. V. 90. P. 12-38. https://doi.org/10.1016/j.paerosci.2016.12.003

[5] Ландау Л.Д. // ПММ. 1945. Т. 9. В. 4. С. 286-292.

[6] Whitham G.B. // Commun. Pure Appl. Math. 1952. V. 5. N 3. P. 301-348. https://doi.org/10.1002/cpa.3160050305

[7] Rao P.S. // Aeronaut Q. 1956. V. 7. N 1. P. 21-44. https://doi.org/10.1017/S0001925900010118

[8] Потапкин А.В., Москвичев Д.Ю. // ПМТФ. 2011. Т. 52. № 2. C. $15-26$.

[9] Potapkin A.V., Moskvichev D.Yu. // Shock Waves. 2014. V. 24. N 4. P. 429-437. https://doi.org/10.1007/s00193-014-0503-x

[10] Potapkin A.V., Moskvichev D.Yu. // Shock Waves. 2018. V. 28. N 6. P. 1239-1249. https://doi.org/10.1007/s00193-018-0817-1

[11] Красильщиков А.П., Гурьяшкин Л.П. Экспериментальные исследования тел вращения в гиперзвуковых потоках. М.: Физматлит, 2007. 208 с 